\title{
COSMOPOLITANS IN AUSTRALIAN AND NEW ZEALAND HEALTH CARE SYSTEMS
}

\author{
Tanisha Jowsey ${ }^{1}$
}

\begin{abstract}
Health systems are abstract spaces in which cosmopolitanisms of care emerge. This article identifies four key types of care cosmopolitans: health care practitioners, health care students, patients, and informal carers of patients. Care cosmopolitans are individuals who enter into health systems from their various angles and draw upon their individually-held cultures, experiences and knowledge - aided by technology and salient discursively-operationalised ideas - to manage their own or other people's health. To illustrate, I first explore the enculturating processes of medical education - including training in cultural competence and cultural safety - in terms of the way they inform students and health care practitioners as care cosmopolitans. Then, taking the case of chronic illness, I turn to patients and informal carers, who navigate tensions in their existing and intimate relationships, and where different levels of knowledge, common heuristics, and access to technology influence their practices of care. In discussing the nuances of care cosmopolitans in these contexts, I draw on data collected in Australia and New Zealand over an eight year period (2010-2018).
\end{abstract}

Keywords: cosmopolitan; health care professional; informal carer; patient; student

\section{INTRODUCTION}

It is difficult to identify one unified definition of cosmopolitanism in the extant literature on the topic. This perhaps reflects the unending horizon of its application to understanding complex and increasingly transnational societies and their people (Beck and Sznaider 2010; Hannerz 2006; Pollock et al. 2000). I see cosmopolitanism as a melting pot of cultures from many regions of the world; a space in which cosmopolitan travellers bring their variously-held lenses to bear on present - and often unusual or foreign - situations. Several 
terms found in the literature offer insight into where the boundaries of cosmopolitanisms of care might lie. According to Hannerz (1990, 240), in his critique of cosmopolitanism, the 'cosmopolitan' - can, debatably, harbour only a superficial engagement with the Other. While they might embrace the alien culture they do not become committed to it.'All the time he [sic] knows where the exit is' (Hannerz 1990, 240). At the same time, the cosmopolitan can be open to deeper engagement with cultural diversity in many forms (Hannerz 1990), and able to recognise his or her own subjectivities in relation to cosmopolitanism more broadly. Second, 'cosmopolitan competence' is an attribute that a person applies in his or her effective acculturation of other cultures' values, beliefs, practices and ways of being. Third, a 'cosmopolitan orientation' refers to the specific facet of cosmopolitanism with which the person is concerned and actively engaged. This third term raises an important notion that the individual is not always oriented toward all cosmopolitanism facets with which he or she has awareness of. This is, arguably, why a definition of cosmopolitanism is so fraught; as soon as we have described the view ahead so that someone might accurately understand what we see, we realise that there is also a view from behind, and beside, and afar, and so on (this point is beautifully demonstrated in the current cosmopolitanism debate between Rapport and Lewis (Lewis 2016; Rapport 2012; Rapport 2017)). Cosmopolitanism then, goes beyond the binary limitations of concepts such as globalisation and transnationalism, to focus instead on the milieu of orientations and interactions of people with elements of social processes, systems, other peoples; of which they may be conscious or unconscious. It increasingly incorporates the way individuals gain understanding of knowledge and practices in the world, as well as the outside influences on the individual's conscious capacity to act and interact with these elements, knowledge and practices. Cosmopolitanism is increasingly influential in the way that social and political scientists conceptualise complex systems, and indeed, the bearing that such complexity holds on the individual (Rapport 2012; 2017). Yet Beck and Sznaider warn us, 'The boundaries separating it from competitive terms like globalisation, transnationalism, universalism, glocalization, etc. are not distinct and internally it [cosmopolitanism] is traversed by all kinds of fault lines' (Beck and Sznaider 2010, 382). Such fault lines become visible through environments and practices of care.

Here I extend the scope of cosmopolitanism by exploring it in terms of care. A care cosmopolitanism is a space in which people bring their variously-held ideas, practices, and knowledge concerning health and health care to bear on present - and often unusual or foreign - situations. Four key types of care cosmopolitans are identifiable within NZ and Australian health care systems. 
These types are: health care students who are liminally-positioned between the general public and health care practitioners; health care practitioners (doctors, nurses, allied health care professionals, complementary health care practitioners, and so on); patients (sometimes called people with health concerns, health system end-users, health care consumers, or the general public), and informal carers of people with health concerns (usually family or close friends who have had little or no formal clinical training). With particular attention to health care students and informal carers, I demonstrate ways in which the orientations of care cosmopolitans differ from one another and inform people's ideas and practices, and ways in which both cultural responsiveness and technology make possible a cosmopolitanism of care, from across oceans to within private homes.

Four sources of data inform this research. First is my informal observations as a medical anthropologist working in a New Zealand medical school. Second is data formally collected for my ethnographic doctoral research (Jowsey 2013) concerning people with chronic illness. Thirdly, I draw on my experiences as a New Zealander patient accessing Australian healthcare services from 2005 to 2014 (informal observations). Fourth, is ethnographic research concerning a student training programme called Urgent and Immediate Patient Care Week in Auckland (Jowsey and Smith 2018). The next section sets the context with a description of the health systems and population needs in New Zealand and Australia, which necessarily inform the ways in which cosmopolitans within each system view and interact with it.

CONTEXT: NEW ZEALAND AND AUSTRALIA

New Zealand and Australia's health systems are informed by their different geographies, populations, socio-political and ethnic-relation histories, and governing structures. Yet despite their contextual differences, there are many similarities in the way health care providers are educated and the ways in which health care is provided.

New Zealand's land size is $268,021 \mathrm{~km}^{2}$ and in 2018 its population was estimated at 4,885,300 (Stats NZ Tatauranga Aotearoa 2018). There are two large islands that hold the majority of New Zealand's population between them, and several smaller islands surrounding them. Most of the population live in major cities. New Zealand has one central government with Parliament based in Wellington, which is supported by multiple governing councils throughout the country. New Zealand offers 'universal health coverage', which Kieny and Evans define in the following way; 
Universal health coverage (UHC), sometimes called universal coverage, is the aspiration that all people obtain the health services they need without suffering financial hardship paying for them. This requires coverage with a range of promotive, preventive, curative, rehabilitative and palliative services, and in particular coverage with services linked to the current health-related Millennium Development Goals and to non-communicable diseases and injuries. (Kieny and Evans 2013, 305)

New Zealand's health system therefore operates under the tenet 'that universal coverage mitigates the inequities in getting access to and paying for health care' (Blendon et al. 2002: 182). Operating with and within this system are forprofit and not-for-profit health care services, as well as private health insurance companies. Research by Schoen and colleagues of countries offering universal health coverage, indicates that low-income adults in New Zealand have relatively high confidence that they will receive high-quality care when they need it (Schoen et al. 2010). However, this belief is not mirrored in outcomes, with the 2013/2014 New Zealand Health Survey reporting that unmet need for primary health care is more common among Māori and Pacific adults and children, and in those living in the most deprived areas (Ministry of Health 2014).

New Zealand has diverse multi-cultural populations, and this is especially so in the major cities. In 2013, $74 \%$ of the population identified with at least one European ethnicity, $15 \%$ of the population identified as Māori (New Zealand's indigenous people), $12 \%$ identified with at least one Asian ethnicity, and seven percent of people identified with at least one Pacific ethnicity (with some people identifying with more than one ethnicity) (Stats NZ Tatauranga Aotearoa 2013). Migration into New Zealand usually sits between 4000 and 6000 migrants per month, with much of this migration coming from Australia, China and the South Pacific region (Stats NZ Tatauranga Aotearoa 2015). As with many western countries, burdens to the New Zealand health system stem primarily from ageing populations and the increasing prevalence of chronic illness, coupled with a shrinking healthcare workforce and increasing fiscal pressures. There are significant health disparities between Māori, Pacific Islands and New Zealand European populations (Anderson et al. 2006; Kessaram et al. 2015). Carter and colleagues note that life expectancy has increased in New Zealand since 1981 but disproportionately; with increases being greater among non-Māori than Māori, high income than low income, and never-smokers than current smokers (Carter, Blakely, and Soeberg 2010).

In contrast, Australia's land size $\left(7,692,024 \mathrm{~km}^{2}\right)$ is considerably larger than that 
of New Zealand and in 2018 its population was estimated at 25,006,923 (Australian Bureau of Statistics 2018). Australia has one Commonwealth (federal) Government supported by local governments in seven States and two Territories. Funding for Australia's health system is shared between the Commonwealth Government and the State and Territory Governments. As with New Zealand, much of the population (64\% in 2010) is condensed around major cities (Australian Institute of Health 2012). In 2011, Australia’s indigenous population - Aboriginal and Torres Strait Islander people - was estimated to be 669,900 people, which was $3 \%$ of the total population, with almost half $(45 \%)$ of Aboriginal people living in 'very remote' areas. Twenty-seven percent of Australia's population in 2011 was born overseas (Australian Institute of Health and Welfare 2014a). There are significant health disparities between indigenous and nonindigenous people in Australia (Altman, Biddle, and Hunter 2008; Anderson et al. 2006; Australian Institute of Health and Welfare 2014a). In 2009, life expectancy in Australia was 79.3 years for males and 83.9 years for females (Australian Institute of Health 2012). For Aboriginal and Torres Strait Islander people, however, life expectancy was twelve years less for males and ten years less for females (Australian Institute of Health 2012). Rates of smoking and risky alcohol consumption were significantly higher among indigenous than non-indigenous people. Social disadvantage was higher among indigenous and migrant populations than non-indigenous populations.

As with New Zealand, Australia's health system also provides universal health coverage, and it is also faced with burdens to the health system associated with ageing populations and increasing prevalence of chronic illness (Glasgow et al. 2008). Health care services in New Zealand and Australia are similarly structured; primary health care is primarily managed through general practices and hospitals, several primary health care organisations are located within each district (managed by District Health Boards in New Zealand and by Medicare Locals in Australia) and are accountable for the population residing therein. Each country has indigenous-specific health care services which also contribute to the specific population needs of their district: Australia having community-based Aboriginal Health Services and New Zealand having Maraebased General Practice Clinics. These indigenous-specific health care services tend to be faced with higher workforce turnover pressures than mainstream health care services, and they often employ more locum medical health care practitioners than permanent position medical health care practitioners (this is compounded by rurality and remoteness, especially in Australia). Buykx and colleagues note that in Australia, the constant major restructuring of the health system has negatively informed the capacity of health services to provide quality of care, particularly in rural and remote areas (Buykx et al. 2012). 
The key points to observe in these two settings in terms of cosmopolitanism, are:

- New Zealand and Australia's health systems share many similarities in terms of universal health coverage, their complexity, and in terms of burdens to the health system (such as avoidable hospitalisation, chronic illness burden and workforce shortages);

- Immigrant populations and cultural diversity are substantial in both countries; this means that people in the care cosmopolitanism (accessing health services, learning about care provision and/or providing care) likely have different knowledge, ideologies, language and health practices to other people engaging in the care cosmopolitanism;

- Australia's indigenous population is markedly smaller in terms of its proportion of the total population than is New Zealand's indigenous population (3\% and $15 \%$ respectively);

- New Zealand and Australia's health systems each offer culturally-specific health care services to their indigenous populations through Aboriginal Health Services in Australia and Marae-based General Practice Clinics in New Zealand (though indigenous people can and do also access mainstream health services); and

- The scale of 'remoteness' in Australia is larger than in New Zealand and $45 \%$ of the indigenous population live remotely in Australia; with remoteness presenting significant barriers to their access of health care services.

\section{FOUR KEY TYPES OF CARE COSMOPOLITANS}

Viewing the Australian and New Zealand health care systems as macro-scale examples of care cosmopolitanism, I now attend to four key types of care cosmopolitans that are identifiable within them: health care students, health care practitioners, people with health care concerns (patients), and informal carers. The categorisation of people into these four categories is not a clearcut enterprise. It is possible that the informal carer may also be a patient, and may even also be a medical student. Or there may be times when the health care practitioner becomes somebody else's patient. In such cases, the person's 'cosmopolitan competence' and 'cosmopolitan orientation' are pivotal to their appropriate and/or successful interactions with the care cosmopolitanism.

I suggest here that each of the four types of care cosmopolitan brings specific 
views, ideas, and orientations concerning care, and that this informs people's practices and biographies - both enculturated and acculturated. In this section I briefly explore the orientations of each of the four cosmopolitans before presenting two case studies that serve to illustrate cosmopolitan complexities and the way they present themselves in mundane everyday life. Attention is first given to the health care student, whose training leads to the attributes necessary to become a qualified health care practitioner. Next is the health care practitioner, whose primary concern is - according to the oath at their graduation ceremony - patient safety and quality care. Then I describe cosmopolitan biographies of receivers of that care; patients. Finally, I attend to the informal carer who in many ways creates what Vertovec calls a 'cosmopolitan toolkit' (Vertovec 2009) that is not dissimilar to that of the health care student, and includes explicit cultural materials, attitudes, and rituals that can be deployed as the circumstances require.

\section{Health care students}

Western biomedicine represents an exemplar of globalisation in its global tides of knowledge, material culture, practices, medical students and health professionals. The globalisation of medical education is a driver and a reflector of significant ethnic diversity among health care students in New Zealand and Australia (Hawthorne, Minas, and Singh 2004). Ostensibly, international students retain their orientation towards their home cultures, at the same time as they must demonstrate competence in New Zealand and Australian medical schools and the communities in which they reside during their medical education.

As health care students advance through their training they are gradually enculturated into the cosmopolitan ideologies, moralities, and practices of care that are generally shared by health care practitioners. The hidden curriculum is part of this enculturation process (Jaye, Egan, and Parker 2005; 2006). Processes of enculturation and acculturation occur during training in informal and formal learning contexts. As part of their education, health care students in New Zealand attend formal education sessions concerning professionalism and cultural competence where they learn the ideologies of professionalism; cultural safety and competence, and how professionalism and cultural competence are constructed and made evident in practice (Jowsey 2017; Yielder 2004). Indeed, I have personally developed and taught such curricula. Students also observe their peers, colleagues, teachers and health care practitioners in different work-related and social settings; where they make their own informal observations and assessments of where the boundaries of professionalism and 
cultural competence might lie (Bolier et al. 2018; Hawick et al. 2018; Jowsey 2018). Students are encouraged to write and reflect upon such observations - their stories - in personal written portfolios where they demonstrate not only the hidden curriculum but also their 'cosmopolitan competence' and orientations towards cosmopolitanism. This is most notable in their reflections on morality, non-maleficence and beneficence. Early in their training, health care students are taught to 'do no harm' to patients, and the boarders of this meaning are teased out through reflection on ethical care dilemmas and even in clinical reasoning.

They are trained in cultural competence, and here I refer to the clinical culture as much as awareness of cultural diversity and how to address patients - and indeed, other health care practitioners - in culturally-appropriate ways. I have observed that throughout their training, health care students are encouraged to become equally aware of clinical cultures and of cultural competence. This dual emphasis is particularly evident at The University of Auckland, which caters to an ethnically diverse student population in an ethnically diverse city. In terms of the student cosmopolitan orientation, students are encouraged to become aware of ethnic and culturally-diverse needs of their patient populations (by learning key words or phrases in dominant languages of the population, or taking learning modules about culturally-specific care needs of transgender or Deaf patients, for example). At the same time, their orientation toward the desired culture of clinical practice is groomed through reflection on other notions such as professionalism and beneficence, and through key guiding documents such as Good Medical Practice (Medical Council of New Zealand 2013). Added to this process of learning desired practice is a process of gaining insight into the rewards of clinical practice - such as watching a gravely ill patient recover and regain their strength or holding a new born baby - as well as the tough realities of what it sometimes means to be a clinician - to undertake unpleasant procedures, deal with difficult patients, watch patients suffering and even dying despite the clinicians' best efforts - and all the while attempt to maintain a professional level of composure (Bolier et al. 2018).

\section{Health care practitioners}

Biomedicine represents an exemplar of globalisation, with an estimated $41 \%$ of medically qualified professionals in New Zealand in 2012 being international medical graduates (Medical Council of New Zealand 2012), and slightly lower percentages (34.2\%) reported in Australia in 2011 (Australian Institute of Health and Welfare 2014b) (2012 data unavailable). The application of biomedical discourse to local existing health knowledge and practices has been well docu- 
mented in the medical anthropology literature (Guarnaccia and Rodriguez 1996; Kleinman 1980; Van der Geest, Whyte, and Hardon 1996). The notion of cultural brokering previously applied to pharmacists by Whyte, Van der Geest and Hardon in the Social Lives of Medicines (2002) is highly relevant to the ways in which general practitioners in both Australian and New Zealand practice. Over time, health care practitioners selectively acculturate local systems, or ways of operating within these systems, to attend to the needs of their communities (Singer and Baer 1995). They develop preference for certain other health care practitioners and/or services within the system based on their own previous experiences, also illustrating their competence at mediating the formal and informal components of the system. In 2015, my previous general practitioner (GP) in Canberra, for example, had a pin board beside his desk where he had, over many years, placed his hand-written notes containing the contact details of other health care practitioners to whom he preferred to refer his patients. The pin board was an example from his 'cosmopolitan toolkit'. Such preferences were built on his own previous experiences and those of his patients. Over time, my GP learned important information about other health care practitioners, upon which he based decisions and practices. Key information included who:

held expert knowledge;

would 'make time' for the referred patient; and

would send a reply letter to the GP stating the outcome of the referral.

He also learned:

which systems he preferred to deal with

which systems offered easy navigation for either himself or his patients

which systems would offer timely care, quality in coordination and continuity of care

which health care practitioners would offer patient rebates or were more affordable than others; and

which services required knowledge of other related issues such as accessibility (public transport options, availability of free car parking, and so forth). 
One day in 2010 I reported back to my GP the outcome of his referral for me to a neurologist and he was so frustrated by the outcome that he unceremoniously ripped the note containing the neurologist's contact details from his pin board and threw it in the rubbish bin.

Health care practitioners such as GPs can be seen to hold increasing awareness/ competencies of the systemic and individual attributes that make a given health care system into a cosmopolitanism. Through ongoing participation, the health care practitioner's knowledge of members of the cosmopolitanism increases, as does their knowledge of the strengths and pitfalls of services and programs within the system, and of the interactions between the health care system and other systems within society, such as transport, the legal system and education. This knowledge that builds over time and through personal experience is critical to successful functioning of systems within the cosmopolitanism. Such success is undermined by flows of health care professional migration, not so much between health systems (although this is also an issue), but between countries. This is highlighted in the case of Pacific Island and Filipino nurses and caregivers being actively recruited from overseas to move to New Zealand for care of the elderly (Badkar and Manning 2009). In Australia, recruitment from overseas for nursing and caregiving is also rising (Hugo 2009).

\section{Patients}

The patient's priority is to access timely, effective and culturally-appropriate care. In both New Zealand and Australia people are encouraged to enlist with a specific General Practice and to routinely see health care practitioners within that Practice to manage their health. In Australia such enlistment does not necessarily translate into people attending the same practice or consulting the same health care practitioner routinely. Neither does it translate into them viewing the health care practitioner as someone who organises/manages their health care (Dawda et al. 2015). In New Zealand, if patients seek care from a General Practice other than the one they are officially enlisted with then they may be subject to higher consultation fees. This becomes a significant primary health care access and equity issue for transient populations, such as wool handlers in Central Otago.

Patients, as cosmopolitans of care, become increasingly aware of these access and continuity of care issues as they interact with health care services over time and in different spaces. For the patient who does not fluently speak the language offered at the health service they access, additional challenges present themselves (Jowsey, Gillespie and Aspin 2010). Even if the patient does speak 
English, they may not understand the medical terminology used by health care practitioners. The cosmopolitan patient learns these new terms along the way, which inform their navigation of information and health systems. Indigenous patients are faced with further challenges. Studies concerning the experiences of Maori, Aboriginal, and Torres Strait Islander people in health services in New Zealand and Australia report that many have had previous experiences of racism, unprofessional and/or culturally-incompetent care; deterring them from future access to health services (Aspin et al. 2012; McPherson, Harwood, and McNaughton 2003; Reid and Robson 2006). While both New Zealand and Australia offer indigenous-specific health services, many indigenous patients often need to access mainstream health services. For successful health care delivery, mainstream health services need to be attuned to the culturally-specific needs of their service's patient populations. However, knowledge, agency and a cosmopolitan toolkit are also needed on the part of the patient. The successful cosmopolitan patient identifies what culturally-appropriate resources and services are available to them within a given health care context. This might mean, for example, finding out that a 'no more bunda [tobacco] quit smoking' program exists for Aboriginal people; or that staff karakia [Māori prayers or incantations] are available in some mainstream health services to patients either in the evening or upon request; or insisting that a qualified interpreter who is not known to the patient is made available to assist the patient in a health care consultation. What I am suggesting here is not that it is solely up to the patient to discover that such services exist, but that one of the hallmarks of cosmopolitanism for patients is their ability to orient themselves towards opportunities that hold the potential to positively impact their health management.

One further facet of the patient's toolkit toward cosmopolitanisms of care is their electronic literacy, such as their ability to research on the Internet, access electronic health records, or utilise their mobile phones to set up reminders to attend medical appointments. Insufficient knowledge and skills in this domain can lead to disastrous patient outcomes, as evidenced too frequently when people report searching on the Internet for an explanation, diagnosis or treatment (known as 'asking doctor Google') and incorrectly self-diagnose (although Bouwman and colleagues suggest that using the Internet in this way may be a good thing in some cases, and they present such cases where people's searching efforts have resulted in correct diagnoses of rare diseases (Bouwman et al. 2010)).

Informal carers

Informal carers, like medical students, often occupy liminal spaces: they are not 
formally trained in care provision but nevertheless provide care that is essential to the patient's ability to manage their health (van Gennep 1972). Informal carers are cosmopolitans whose practices of care require their transition toward skills and knowledge of illness, health, systems of care and technology; and toward increased intimacy or changes in their existing relationship with the care recipient, whose health becomes a shared focus (Ward et al. 2011). The provision of informal care and support offers informal carers experiential knowledge about the daily lived needs of care recipients and of the formal systems of care with which they engage (Essue et al. 2010). Patient care becomes a moral concern, one that they share with health care practitioners and health care students.

Yet informal carers are also much like patients in terms of their cosmopolitanism and their orientations toward care and health-related practices of daily living. For example, informal carers learn alongside their recipient about the care recipient's illness and associated needs, including how to navigate health systems and learn the language of health care practitioners. They may also undertake Internet searching for health-related information on behalf of their care recipient.

The cosmopolitanism of care greatly informs each of the four types of cosmopolitan in biographical ways. For informal carers who provide care over a long period of time, as in the case of caring for a spouse or parent with chronic illness, the biographical implications can be significant (which my colleagues and I have described elsewhere in terms of care work, self-management partnerships, identity and biographical work (Essue et al. 2010; Jowsey 2011; Jowsey et al. 2013)). The biographical elements will be attended to in the informal carer case study.

\section{COSMOPOLITAN CASE STUDIES}

Blasco's (2010) ethnographic essay concerns the tensions that one of her cosmopolitan informants faced when she left her gipsy family to be with her lover. Close reflection upon the biographical approach to cosmopolitanism that Blasco (2010) has taken raises in me several questions about the positioning of cosmopolitanism within the many 'health care' domains that have emerged in different times and spaces to attend to the ill person. In this next part of the chapter I propose an exploration of the idea of cosmopolitanism as it relates to bodies, patients, and informal carers within and apart from health care systems; across borders and through technologies. These interconnected facets of health care, I suggest, are informed by cosmopolitanism as much as they inform our 
understanding of what cosmopolitanism is and can be. I present two short case studies, the first concerning a health care student in New Zealand, and the second concerning a man in Australia with chronic obstructive pulmonary disease and his wife. The case studies serve to illustrate how the cosmopolitan orientations, enculturation and biographies of people are informed by their positioning within, and in relation to, the cosmopolitanism of care. What they add is a level of specificity that enables us a closer look at the articulations between people's lived experiences and the health care systems that illustrate care cosmopolitanism on a macro level.

Case Study 1: Health care student cosmopolitan

After ten years of researching Australia's health system and the experiences of patients and informal carers within it, I moved to New Zealand to teach in a school of medicine. Although I was trained as an anthropologist, rather than a health care practitioner, I shared with my clinical colleagues a common focus - the health and care of people. This common focus formed the basis of our interaction with one another. One of the most technologically-informed health care education courses that I have contributed to during the past four years is a simulation-based interprofessional training course involving medical, pharmacy, paramedicine and nursing undergraduate students. It offers students the opportunity to work together in simulated clinical scenarios to systematically approach an acutely unwell patient. The course, called Urgent and Immediate Patient Care (UIPC) Week, utilises cutting-edge technology and educational methods, including patient actors and computerised mannequins (Jowsey et al. 2017, Jowsey and Smith 2018) (see figs 1 \& 2).

One day during a lunch break, an overseas student, referred to here as Val, explained to me that although other students seemed to be most anxious about having to make leadership decisions during the simulation scenario, her main concern was with communication and the extra time she needed to interpret what the simulated patient and her team members were saying. This extra time (which was likely to be a matter of seconds) placed additional pressure on her in an already stressful situation. Why would she choose this extra pressure? Why not study at home, I asked. 'I want quality training. New Zealand is good', she replied from under her hijab. In that moment I saw Val as a cosmopolitan; a member of my global singular community of care, who was faced with crossing physical borders as well as metaphorical ones (language, for example) in order to locate herself within a global cosmopolitanism of care.

Val - a cosmopolitan - moved away from her family and loved ones to seek an 


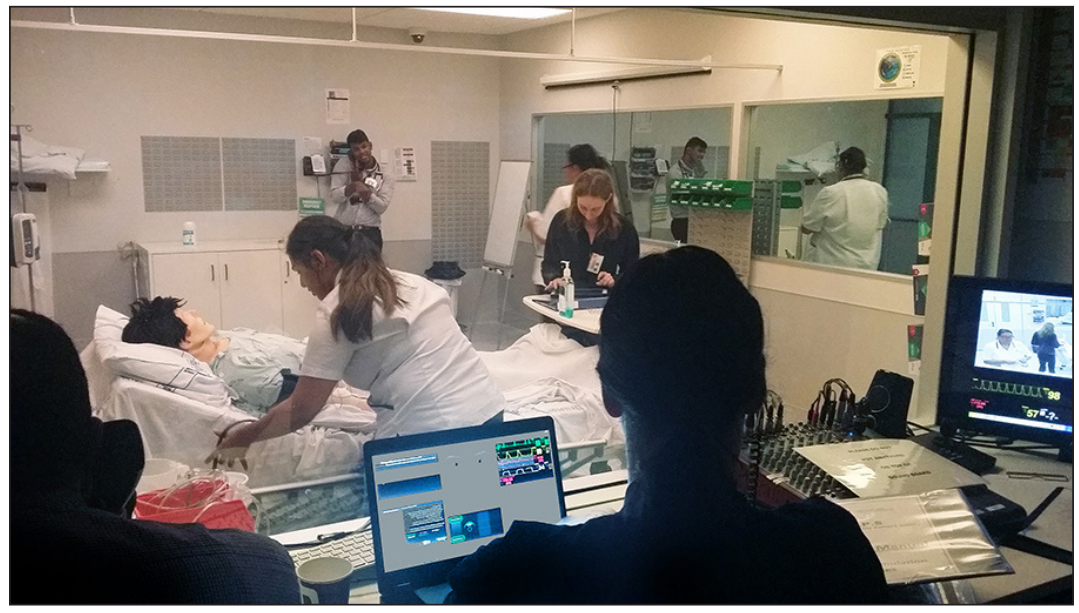

Figure 1. UIPC Week technology

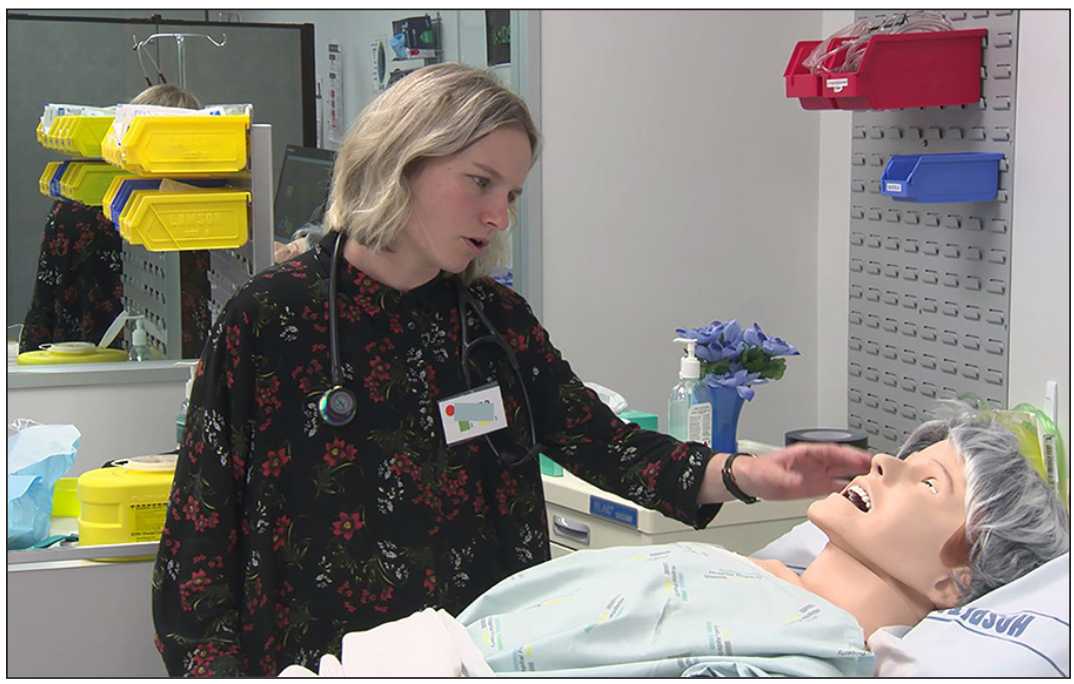

Figure 2. Student with mannequin

education from an institution that she knew had internationally-acknowledged standards; the purpose of which was to better position herself - through obtaining education from this specific institution - against other candidates in future work opportunities. English was not her first language. While other students entered the simulation scenarios and used their mobile phones to look up drug 
interactions and diagnostics, Val used her phone to check translations of what she had heard. Not only did Val appear as a global citizen, but she engaged with modern technologies (the mobile phone) to tap into global knowledge (through the Internet) in the advancement of her education. This education, ten months of which was sought abroad, would serve her local community upon her return. Likewise, it also opened up new potential futures where her education could serve communities of care in a global sense.

Val's case has similar hallmarks to that of 'Vicky' in Hochschild's (2000) ethnographic account of a college-educated school teacher who moves from the Philippines to the United States in order to earn money as a nanny that she can then send back home to support her five children through school, which Hochschild describes as an example of a global care chain (Hochschild 2000). Only, in Val's case, the care chain is one informed by the formal education of care practices from abroad, in what we might call 'export education' (Codd 2004) and also by what Werbner (1999) might frame as an opportunity of the elite. That is, not all higher education students, or even all health care students, have the opportunity to travel internationally to gain health education (see also, Vertovec 2009). Even so, Val's willingness to engage with a new education and health system, and with students, simulated patients, and teachers of different ethnicities, might be 'described as a kind of xenophilia, or penchant for diversity. The experience of living in conditions of diaspora, or in fact engaging in transnational life spread across two or more global settings, exposes individuals to cultural differences that may give rise to such cosmopolitan views' (Vertovec 2009, 6).

\section{Case Study 2: Practices of care and shared identities}

During 2010 I began qualitative research with people living in Canberra and Sydney (Jeon et al. 2010), who themselves had, or cared for someone with, severe chronic illness. The experiences of Caitlin, who cared for her husband Roger in Canberra are used here to illustrate how informal carers can be seen as cosmopolitans of care (Jowsey 2013).

Roger had severe chronic obstructive pulmonary disease (COPD). 'Caitlin did not think of herself as a carer until, due to pneumonia, one day her husband slipped into a coma. At that point Caitlin was catapulted into a medicalised world, one where the inhabitants wore white, spoke quietly and calmly but in a foreign language; one where her husband lay still, not fighting the invading tubes, not disturbed by the constant beeps of machinery' (Jowsey 2013: 81). This sudden and severe change in Roger's condition required health care practition- 
ers to take on responsibility for his health and the needs of his body.

Finally Roger awoke. Responsibility for his care was passed from the hospital clinicians to Caitlin, who took Roger home. 'At home she quickly learned how to operate the supplementary oxygen equipment and to administer prescribed medication, without which he would die' (Jowsey 2013: 81). She learned how to replace an empty oxygen cylinder with a full one in less than sixty seconds. In ongoing processes of trial and error Caitlin obtained the knowledge and skills necessary to assist the health needs of her husband. For years thereafter Caitlin maintained a constant 24 hour mode of caring for Roger.

Caitlin's understanding of Roger's health needs advanced to the point that not only did she demonstrate understanding of how to effectively use technology to assist him, but she also understood the need for a 'hospital-like environment' and she knew how to establish one in their home. Caitlin even started to speak the language of health care practitioners, using terms such as 'dispense medication,' 'hospital discharge' and ' $\mathrm{O}_{2}$ saturation.' Her knowledge and vocabulary also extended into health system domains, evidenced by her capacity to navigate health services, online health information, and health-service-associated paperwork. Almost every time I saw Caitlin she was wearing a tee-shirt that in large letters said 'What is COPD? Ask me about it.' This tee-shirt signalled both her knowledge of COPD and her membership in an Australian-wide support group that had Internet meetings as well as local in-person meetings.

Eighteen months after our last formal interview, Caitlin's husband died.

Caitlin's identity had been catapulted into a care cosmopolitanism by the needs of her sick husband. This is evident in her changing orientations and practices; she gave up previous practices and devoted herself to new practices associated with managing Roger's chronic illness, such as attending to Roger's high-calorie dietary needs, and creating a home hospital environment. She developed knowledge of specific illness management strategies and of how to navigate health care systems to optimise Roger's continuity of care and quality of care. And she operationalised technology - managing oxygen cylinders and concentrators - to support Roger's care needs. These orientations and engagements with cosmopolitanism of care came to an abrupt end with Roger's death, and new orientations and engagements were formed on the basis of her own personal (biographical) needs. Caitlin's transition from 'wife' to 'highly skilled medicalised informal carer' and then to 'widow' required a 'cosmopolitan toolkit' (Vertovec 2009). As a cosmopolitan of care, Caitlin learned and absorbed various elements of the formal care culture that she 
identified as useful in her efforts to meet the needs of her sick husband. These tools became essential when Roger transitioned from hospital to home care. Once Roger passed away Caitlin was in a position to be more selective about which aspects of her caring experience would feature in her future. For example, she continued to wear the COPD tee-shirt, thereby affirming her identity with the COPD community (Jowsey 2013).

\section{DISCUSSION: TECHNOLOGY, ENVIRONMENTS AND SYSTEMS OF CARE}

These two case studies illustrate several aspects of cosmopolitanisms of care. The first is that local and specific instances of those within the healthcare system illustrate the competencies required of those working and studying, and being a consumer within healthcare settings. The second is that healthcare systems bring the cosmopolitanism of care into the classroom, the clinic, and the home where real people - patients, informal carers, health care professionals and students - interact with each other and with practices, knowledge, and repertoires that have cosmopolitan currency around the world. The third aspect of cosmopolitanism illustrated here is how similar the experiences of medical students are, regardless of their location. The same is true for patients and informal carers. Medical students are learning to relieve suffering in ways that are transferable from one healthcare system to another, as when Val eventually returned from her training in New Zealand to work as a doctor in her own country. Caring for chronically ill family members is also a circumstance which evokes similar experiences and challenges the world over. Private home spaces are transformed through medical technology and ways of being, and patients and carers are increasingly engaging in online support groups to share their experiences.

The case studies also illustrate that people's engagement with technology is a critical element of cosmopolitanism generally, and cosmopolitanism of care specifically. Technology's diverse application extends from computerised anaesthetic modelling for application of drugs to specific bodies with specific needs, to the harvesting of health-related information from the MIMs Online (MIMs LTD 2014), or indeed, YouTube (Vance, Howe, and Dellavalle 2009), and even the operation of devices in the home such as oxygen cylinders. Technology traverses many spaces including those between and even within bodies, between private and public information, and between geographic regions. It is, much like the unending horizon, borderless. This unbounding quality of technology in many ways removes borders and dualisms, and increases flows of information. Health care practitioners now have, at the click of a button, an endless ocean of information on any given topic. In a functional sense, cosmopolitanism 
is made possible through technology. Both Australia and New Zealand, like many other countries, have spent considerable time and resources attending to the role that the Internet can play in holding personalised electronic health records (Mount et al. 2000; Poissant et al. 2005). The potential of the e-health record for disintegrating borders between health care practitioners, health services and people accessing them, is incredible. Will we see the day when a cosmopolitan can obtain a current and accurate electronic copy of his or her health record from any health system in the world? While the systems needed to ensure patient confidentiality, record accuracy and detail, and patient quality and safety are now in their infancy, the possibilities that their refinement holds for cosmopolitans in care are enormous.

Cosmopolitanism as it relates to bodies, patients, and health care systems is also made possible through the application of care models in multiple systems and sites around the world. Take, for example, the Chronic Care Model (Coleman et al. 2009; Wagner 1998; Wagner, Austin, et al. 2001; Wagner, Glasgow, et al. 2001; Wagner et al. 2005). This patient-centric model proposes to improve quality of care and patient outcomes by centralising the needs of patient and empowering the patient to take an active role in their management (Bodenheimer, Wagner, and Grumbach 2002; Wagner, Glasgow, et al. 2001). The model's value is demonstrated by hundreds of diverse organisations around the globe that use the model to structure their care ethos. Part of the success of the model lies in its capacity to attend to the diverse care needs of people; a diversity informed by ethnicity, culture, socio-economic status, access to resources, health literacy, mobility, multimorbidity and agency. Models of care such as the Chronic Care Model cater to the needs of cosmopolitans by mobilising resources to focus on the one thing that all cosmopolitans of care value: their health.

\section{CONCLUSION}

The tensions between local and foreign are tensions that cosmopolitans in Australia and New Zealand's health care systems grapple with by resituating themselves in relation to previously-held beliefs, previous experiences, and new ideas and experiences. Their cosmopolitan subjectivities become clear throughout the telling of their stories and the way they engage with new experiences of care (see also Blasco 2010, 404; Pollock 2000, 586). This article has interpreted cosmopolitanism of care in terms of health systems in New Zealand and Australia, by locating four key cosmopolitans within them: health care practitioners, health care students, people engaging with health services to manage their health care needs (patients), and informal carers. Illustration of the tactile ways in which cosmopolitanism informs people's experiences of health care 
systems and practice was made through the clinical learning experiences of an overseas student in New Zealand and the informal care practices of a woman in Australia. These illustrations focused on what it means to have cosmopolitan awareness, competence and orientation towards cosmopolitanism of care. What will the future cosmopolitan of care look like in Australia and New Zealand? Increasingly, technology is influencing the ways in which cosmopolitans engage with health systems. It is only a matter of time before electronic health records operationalise in effective and secure ways, and before they become accessible from any point on the planet. It seems even the imagined futures of Star Trek are at our doorstep with the invention of a Qualcomm Tricorder [a handheld diagnostic tool] now available to health care practitioners and even to patients themselves (Qualcomm Tricorder xprize.org 2015).

Equally influential are advances in cultural competence and responsiveness from all four types of care cosmopolitans, and from the institutions they represent and engage with. Both Australia and New Zealand have implemented significant steps towards improving cultural safety for their indigenous and ethnically diverse populations. The gap in life expectancy between indigenous and non-indigenous people remains substantial in both countries but initiatives are underway. Could the future offer us a reality where there was no gap? Or indeed, where care cosmopolitans did not have memories of culturally incompetent care? It will take the efforts of all kinds of care cosmopolitans to make this a reality.

NOTE

1 Tanisha is a medical anthropologist and lecturer at the Centre for Medical and Health Sciences, University of Auckland. Tanisha is a fifth generation Pakeha New Zealander from North Canterbury. She has many years of research and teaching experience in medical anthropology and public health. Tanisha has worked with vulnerable and disadvantaged populations, including Indigenous Australians, migrants, and people with dementia and other chronic illnesses.

Email: t.jowsey@auckland.ac.nz

\section{REFERENCES}

Altman, J.C., N. Biddle, and B. Hunter. 2008. 'How Realistic are the Prospects for "Closing the Gaps" in Socio-economic Outcomes for Indigenous Australians'? CAEPR Discussion Paper No.287/2008. Canberra: Australian National University. 
Anderson, I., S. Crengle, M.L. Kamaka, T-H. Chen, N. Palafox, and L. JacksonPulver. 2006. 'Indigenous Health in Australia, New Zealand, and the Pacific'. The Lancet 367 (9524): 1775-1785.

Aspin, C., N. Brown, T. Jowsey, L.Yen, and S. Leeder, S. 2012. 'Strategic Approaches to Enhanced Health Service Delivery for Aboriginal and Torres Strait Islander People with Chronic Illness: A qualitative study'. вмС Health Services Research 12 (1):143-152. doi:10.1186/1472-6963-12-143

Australian Bureau of Statistics. 2018. 'Population Clock'. Accessed 14 August 2018 from http://www.abs.gov.au/

Australian Institute of Health. 2012. 'Australia's Health 2012. Canberra: AIHw.

Australian Institute of Health and Welfare. 2014a. 'Australia's Health 2014'. Canberra: AIHw.

- 2014b. 'Medical Workforce 2012'. National Health Workforce Series No. 8. Canberra: AIHW.

Badkar, J., and R. Manning. 2009. 'Paid Caregivers in New Zealand: Current Supply and Future Demand'. New Zealand Population Review 35:113-127.

Beck, U. 2011. 'Cosmopolitanism as Imagined Communities of Global Risk'. American Behavioral Scientist 55 (10):1346-1361. doi: 10.1177/0oo2764211409739

Beck, U., and N. Sznaider. 2006. 'A Literature on Cosmopolitanism: An Overview'. The British Journal of Sociology 57 (1):153-164. doi: 10.1111/j.14684446.2006.00098.x

- 2010. 'Unpacking Cosmopolitanism for the Social Sciences: A Research Agenda. The British Journal of Sociology 61(s1):381-403.

Blasco, P.G. 2010. 'The Fragility of Cosmopolitanism: A Biographical Approach'. Social Anthropology 18 (4):403-409.

Blendon, R.J., C. Schoen, C.M. DesRoches, R. Osborn, K.L. Scoles, and K. Zapert. 2002. 'Inequities in Health Care: A Five-Country Survey'. Health Affairs $21(3): 182-191$.

Bodenheimer, T., E.H. Wagner, and K. Grumbach, K. 2002. 'Improving primary 
care for patients with chronic illness: the chronic care model, Part 2'. JAMA 288 (15):1909-1914.

Bolier, Melissa, Karolina Doulougeri, Joy de Vries, and Esther Helmich. 2018. "You put up a certain attitude": a 6-year qualitative study of emotional socialisation'. Medical Education 30 July 2018, 1-11. doi: 10.1111/medu.13650.

Bouwman, M.G., Q.G. Teunissen, F.A. Wijburg, and G.E. Linthorst. 2010. “Doctor Google" Ending the Diagnostic Odyssey in Lysosomal Storage Disorders: Parents Using Internet Search Engines as an Efficient Diagnostic Strategy in Rare Diseases'. Archives of Disease in Childhood. Accessed 22 August 2018 from https://adc.bmj.com/content/archdischild/early/2010/o4/22/ adc.2009.171827.full.pdf

Buykx, P., J.S. Humphreys, R. Tham, L. Kinsman, J. Wakerman, A. Asaid, and K. Tuohey. 2012. 'How Do Small Rural Primary Health Care Services Sustain Themselves in a Constantly Changing Health System Environment'? BMC Health Services Research 12 (1): 81.

Carter, K.N., T. Blakely, T., and M. Soeberg. 2010. 'Trends in survival and life expectancy by ethnicity, income and smoking in New Zealand: 1980 os to 200os'. Clinical Correspondence 3: 5 .

Codd, J. 2004. 'Export Education and the Commercialisation of Public Education in New Zealand'. New Zealand Annual Review of Education 13 (1): 21-42

Coleman, K., B.T. Austin, C. Brach, and E.H. Wagner. 2009. 'Evidence on the Chronic Care Model in the New Millennium'. Health Affairs 28 (1):75-85.

Dawda, P., I.S. McRae, L. Yen, M.M. Islam, N. Bagheri, T. Jowsey, ... and A. Parkinson. 2015. 'Does it Matter Who Organises your Health Care'? International Journal of Integrated Care 15 (2):1-11.

Essue, B.M., T. Jowsey, Y-H. Jeon, M. Mirzaei, C.L. Pearce-Brown, C. Aspin, and T.P. Usherwo. 2010. 'Informal Care and the Self-Management Partnership: Implications for Australian Health Policy and Practice.' Australian Health Review 34:(414-422).

Guarnaccia, P.J., and O. Rodriguez. 1996. 'Concepts of Culture and their Role in the Development of Culturally Competent Mental Health Services'. Hispanic Journal of Behavioral Sciences 18 (4): 419-443. 
Glasgow, N., N. Zwar, M. Harris, M., I. Hasan, and T. Jowsey. 20o8. 'Australia' In Managing Chronic Conditions: Experience in Eight Countries (Vol. Observatory Studies Series No. 15), edited by E. Nolte, C. Knai, and M. McKee, 131-16o. European Observatory on Health Systems and Policies. Denmark: wHo Regional Office Europe.

Hannerz, U. 1990. 'Cosmopolitans and Locals in World Culture. Theory, Culture and Society 7 (2):237-251.

Hannerz, U. 2006. Two Faces of Cosmopolitanism: Culture and Politics. Statsvetenskaplig Tidskrift 107 (3): 199-213.

Hawick L, J. Cleland, and S. Kitto. 2018. “I Feel Like I Sleep Here”: How Space and Place Influence Medical Student Experiences'. Medical Education June 22:1-12.

Hawthorne, L., I.H. Minas, and B. Singh. 2004. 'A Case Study in the Globalization of Medical Education: Assisting Overseas-Born Students at the University of Melbourne'. Medical Teacher 26 (2):150-159.

Hochschild, A.R. 200o. The Nanny Chain. American Prospect 11 (4):32-36.

Hugo, G. 2009. 'Care Worker Migration, Australia and Development'. Population, Space and Place 15 (2):189-203.

Jaye, C., T. Egan, and S. Parker. 2005. 'Learning to be a Doctor: Medical Educators Talk about the Hidden Curriculum in Medical Education'. Focus on Health Professional Education: A Multi-Disciplinary Journal 7 (2):1-17.

- 2006. “Do as I Say, Not as I Do": Medical Education and Foucault's Normalizing Technologies of Self'. Anthropology and Medicine 13 (2):141-155.

Jeon, Y-H., T. Jowsey, L. Yen, N.J. Glasgow, B. Essue, ... C. Aspin. 2010. 'Achieving a balanced life in the face of chronic illness'. Australian Journal of Primary Health 16: 66-74.

Jowsey, T. 2013. Chronic illness time. (PhD thesis), Australian National University, Canberra.

- 2017. 'Narrative Medicine: 102 poetic and artistic collected works of medical students at The University of Auckland'. Auckland: Compassion Publishers. 
- 2018. 'Place and Space Inform Medical Professionalism'. Medical Education [in-press]

Jowsey, T., J. Gillespie, J. and C. Aspin. 2010. 'Effective Communication is Crucial to Self-Management: The Experiences of Immigrants to Australia Living with Diabetes'. Chronic Illness 7 (1): 6-9.

Jowsey, T., I. McRae, M. Banfield, J. Gillespie, and L. Yen. 2013. 'Time to Care? Health of Informal Older Carers and Time Spent on Health Related Activities: An Australian Survey. B Mc Public Health 13, 374-394.

Jowsey, T., T-C. Yu, G. Ganeshanantham, J. Torrie, A.F. Merry, W. Bagg, K. Bacal, and J. Weller. 2017. 'Ward Calls Not So Scary for Medical Students after Interprofessional Simulation Course: A Mixed Methods Cohort Evaluation Study'. BMJ Simulation and Technology Enhanced Learning. bmjstel-2017-000257

Jowsey, T., Smith, R. 2018. Prepared to Care. Documentary film produced by T. Jowsey and R. Smith. Auckland. DVD, 26 mins. https://vimeo.com/287166705

Kessaram, T., J. McKenzie, N. Girin, A. Roth, P. Vivili, G. Williams, and D. Hoy. 2015. 'Noncommunicable Diseases and Risk Factors in Adult Populations of Several Pacific Islands: Results from the WHO STEPwise Approach to Surveillance'. Australian and New Zealand Journal of Public Health 39 (4):336-343.

Kieny, M-P. and D.B. Evans. 2013. 'Universal Health Coverage'. Eastern Mediterranean Health Journal 19 (4):305.

Kleinman, A. 1980. Patients and Healers in the Context of Culture: An Exploration of the Borderland between Anthropology, Medicine, and Psychiatry. California: University of California Press.

Lewis, Brigitte. 2016. 'Multiple Peripherals One Cosmopolitanism: Rights-based Feminism and the Globe-trotting Pick-up Artist'. Sites 13 (1):1-23. http:// dx.doi.org/10.11157/sites-vol13issiid 328

McPherson, K., M. Harwood, and H. McNaughton. 2003. 'Ethnicity, Equity, and Quality: Lessons from New Zealand'. BMJ 327 (7412): 443-444.

Medical Council of New Zealand. 2012. 'Workforce Survey 2012'. Accessed 18 December 2015 from https://www.mcnz.org.nz/assets/News-and-Publications/ Workforce-Surveys/2012.pdf 
Medical Council of New Zealand. 2013. 'Good Medical Practice'. Accessed 20 November 2015 from https://www.mcnz.org.nz/news-and-publications/goodmedical-practice/

MIMS LTD. 2014. 'MIMS Online.' Accessed o2 June 2015, from http://www.mimsonline.co.nz/Default.aspx

Ministry of Health. 2014. 'Annual Update of Key Results 2013/14: New Zealand Health Survey'. Wellington: Ministry of Health

Mount, C.D., C.W. Kelman, L.R. Smith, and R.M. Douglas. 20oo. 'An Integrated Electronic Health Record and Information System for Australia'? Medical Journal of Australia 172 (1):25-27

Poissant, L., J. Pereira, R. Tamblyn, R., and Y. Kawasumi. 2005. 'The Impact of Electronic Health Records on Time Efficiency of Physicians and Nurses: A Systematic Review'. Journal of the American Medical Informatics Association 12 (5): 505-516.

Pollock, S., H.K. Bhabha, C.A. Breckenridge, and D. Chakrabarty. 20oo. 'Cosmopolitanisms'. Public Culture 12 (3):577-589.

Qualcomm Tricorder xprize, 2015. 'Qualcomm Tricorder xprize Get your Trek On'. Accessed 20 November 2015 from http://tricorder.xprize. org/?gclid=CjoKEQiAg7ayBRD8qqSGt-fj6uYBEiQAucjOwSDIjwLMP2apPB5poqfo2N_lhJcKoZ7TiQwiguJhEnsaAseY8P8HAQ

Rapport, N.J. 2012. Anyone, the Cosmopolitan Subject of Anthropology. Oxford: Berghahn.

- 2017. 'Towards a Cosmopolitan Anthropology of Anyone: A Response to Brigitte Lewis'. Sites 14 (2):1-13.

Reid, P. and B. Robson. 2006. 'The State of Māori Health'. In State of the Māori Nation: Twenty-First Century Issues in Aotearoa, edited by M Mulholland, 17-30. Auckland: Reed.

Schoen, C., R. Osborn, D. Squires, M.M. Doty, R. Pierson, and S. Applebaum. 2010. 'How health insurance design affects access to care and costs, by income, in eleven countries. Health Affairs 29 (12):2323-2334. 
Singer, M. and H. Baer. 1995. Critical Medical Anthropology. Amityville, N.Y.: Baywood Publishing Company.

Stats NZ Tatauranga Aotearoa. 2013. '2013 Census - Major ethnic groups in New Zealand'. Accessed 11 September 2015 from http://www.stats.govt.nz/ Census/2013-census/profile-and-summary-reports/infographic-cultureidentity.aspx

- 2015. 'International Travel and Migration: information releases'. Accessed 10 September 2015 from http://www.stats.govt.nz/browse_for_stats/population/ Migration/IntTravelAndMigration_HOTPDec14.aspx

- 2018. 'Stats NZ Population.' Accessed 14 August 2018 from https://www. stats.govt.nz/

Van der Geest, S., S.R. Whyte, and A. Hardon.1996. 'The Anthropology of Pharmaceuticals: A Biographical Approach'. Annual Review of Anthropology 251(1): 153-178.

Van Gennep, A. 1972. The Rites of Passage. Chicago:The University of Chicago Press.

Vance, K., W. Howe, and R.P. Dellavalle. 2009. 'Social Internet Sites as a Source of Public Health Information'. Dermatologic Clinics 27 (2):133-136.

Vertovec, S. 2009. 'Cosmopolitanism in Attitude, Practice and Competence'. Accessed 20 November 2015 from http://pubman.mpdl.mpg.de/pubman/item/ escidoc:1126666/component/escidoc:2056850/WP_09-08_Vertovec_Cosmopolitanism.pdf

Wagner, E. 1998. 'Chronic Disease Management: What Will It Take to Improve Care for Chronic Illness'? Effective Clinical Practice 1(1):2-4

Wagner, E.H., B.T. Austin, C. Davis, M. Hindmarsh, J. Schaefer, and A. Bonomi. 2001. 'Improving Chronic Illness Care: Translating Evidence into Action'. Health Affairs 20 (6): 64-78.

Wagner, E., R.E. Glasgow, C. Davis, A.E. Bonomi, L. Provost, D. McCulloch, P. Carver, C. Sixta. 2001. 'Quality Improvement in Chronic Illness Care: A Collaborative Approach.' J Quality Improvement 27 (2): 63-80.

Wagner, E.H., S.M. Bennett, B.T. Austin, S.M. Greene, J.K. Schaefer, and M. Vonkorff. 
2005. 'Finding Common Ground: Patient-Centeredness and Evidence-Based Chronic Illness Care'. Journal of Alternative Complementary Medicine 11 (Suppl 1):7-15.

Ward, N.J., T. Jowsey, P.J. Haora, C. Aspin, and L.E. Yen. 2011. 'With Good Intentions: Complexity in Unsolicited Informal Support for Aboriginal and Torres Strait Islander Peoples. A Qualitative Study'. BMC Public Health 11 (1): 686-695.

Werbner, P. 1999. 'Global Pathways. Working Class Cosmopolitans and the Creation of Transnational Ethnic Worlds'. Social Anthropology 7 (1):17-35.

Whyte, S.R., S. Van der Geest, and A. Hardon. 2002. Social Lives of Medicines. Cambridge. Cambridge University Press.

Yielder, J. 2004. 'An Integrated Model Of Professional Expertise and its Implications for Higher Education'. International Journal of Lifelong Education $23(1): 60-80$. 